\title{
Pengaruh Celebrity Endorser Media Sosial (Instagram) dan Kualitas Produk terhadap Keputusan Pembelian Sate Taichan “Goreng” (Studi Pada Konsumen Sate Taichan “Goreng” Cabang Tebet)
}

\author{
Shara Chumairah ${ }^{1}$, Fortuna Zain Hamid ${ }^{2}$, Menik Wijiyanty ${ }^{3}$ \\ Administrasi Bisnis Terapan, Politeknik Negeri Jakarta, Kukusan, Beji, Depok City, West Java 16425 \\ e-mail: ${ }^{1}$ sharachumairaah@gmail.com
}

\begin{abstract}
This study aimed to determine the effect of the celebrity endorser (Rachel Vennya) and product quality to purchasing decision, which was conducted on 100 people Sate Taichan "Goreng" buyers in Tebet branch using non-probability sampling technique with incidental sampling approach. The research method used in this research was quantitatice with survey method aproach. The data in this study were tested using classical assumptions consisting of normality test, multicollinearity test, and heteroscedasticity test. Futhermore, the hypotesis was tested using by using multiple linear reggresion analysis, coefficient of determination $\left(R^{2}\right), t$ test, and $f$ test. This study uses data analysis techniques with the help of SPSS (Statistical Package for Social Science) program version 23.0.

The empirical test results indicate that celebrity endorser and product quality together have a positive influence on purchasing decision product of Sate Taichan "Goreng” Tebet brach by 42,5\%. Partially, the results of the analysis on celebrity endorser shows that this variable affect purchasing decisions by $40,83 \%$ with $t$ count $=7.051>t$ table $=1.66071$ and a significance value of $0.000<0.10$. While the product quality variable has an effect on the purchase decision of $13.03 \%$ with $t$ count $=1.673>$ t table $=1.66071$ and a significance value of $0.098<0.10$
\end{abstract}

Keywords: celebrity endorser, product quality, purchasing decision

\section{Abstrak}

Penelitian ini bertujuan untuk mengetahui pengaruh langsung celebrity endorser (Rachel Vennya) dan kualitas produk terhadap keputusan pembelian. Sampel pada penelitian ini sebanyak 100 responden konsumen Sate Taichan "Goreng” Cabang Tebet dan teknik yang digunakan adalah teknik non-probability sampling dengan pendekatan incidental sampling. Penelitian ini menggunakan metode kuantitatif dan pendekatan metode survey. Data pada penelitian ini dilakukan pengujian asumsi klasik yang terdiri dari uji normalitas, uji multikolinearitas, dan uji heterokedastisitas. Selanjutnya hipotesis diuji dengan menggunakan metode analisis regresi linier berganda, analisis koefisien determinasi $\left(\mathrm{R}_{2}\right)$, uji $\mathrm{t}$, dan uji $\mathrm{f}$. Penelitian ini menggunakan teknik analisis data dengan bantuan program SPSS (Statistical Package for Sosial Science) versi 23.0.

Hasil penelitian ini menunjukkan bahwa celebrity endorser dan kualitas produk secara bersama-sama berpengaruh terhadap keputusan pembelian konsumen Sate Taichan “Goreng” Cabang Tebet sebesar 42,5\%. Secara parsial, hasil analisis pada celebrity endorser menunjukkan bahwa variabel tersebut berpengaruh terhadap keputusan pembelian sebesar $40,83 \%$ dengan $t_{\text {hitung }}=7,051>t_{\text {tabel }}=1,66071$ dan nilai signifikansi sebesar $0,000<0,10$. Sedangkan variabel kualitas produk berpengaruh terhadap keputusan pembelian sebesar $13,03 \%$ dengan $t_{\text {hitung }}=1,673>t_{\text {tabel }}=1,66071$ dan nilai signifikansi sebesar 0,098 $<0,10$

Kata Kunci : celebrity endorser, kualitas produk, keputusan pembelian 


\section{PENDAHULUAN}

Dalam menarik perhatian konsumen, pemakaian jasa celebrity seringkali digunakan dalam sebuah iklan untuk mendukung penjualan suatu produk. Celebrity endorser adalah strategi pemasaran dengan menggunakan selebriti yang disukai dan dihormati oleh khalayak dan diharapkan dapat mempengaruhi sikap dan perilaku konsumen yang baik terharap produk yang didukung (Shimp, 2003:460). Perusahaan harus memilih endorser yang cocok untuk menyampaikan pesan yang diinginkan kepada konsumen, sehingga nantinya celebrity endorser tersebut dapat berperan juga sebagai opinion leader dan diharapkan akan bertambahnya kesadaran masyarakat terhadap produk. Penggunaan endorser saat ini dapat dikatakan sebuah strategi pemasaran yang efektif. Suatu produk yang menggunakan celebrity sebagai endorser atau pendukung iklan, akan lebih melekat dibenak masyarakat karena seorang celebrity yang terkenal akan lebih mudah untuk mempengaruhi (influence) perilaku serta persepsi konsumen.

Salah satu selebriti asal Indonesia yang seringkali mengiklankan produk adalah Rachel Vennya. Ia melakukan kegiatan promosi pada akun media sosialnya yang mempunyai pengikut mencapai 2 juta per April 2018 pada akun Instagram miliknya (@rachelvennya). Melihat besarnya nama Rachel pada platfom Instagram, banyak pelaku usaha melakukan kerja sama dengan Rachel untuk mempromosikan produk mereka melalui akun media sosial milik Rachel atau dapat dikatakan Rachel berperan sebagai endorser. Rachel mempunyai pengikut yang begitu banyak pada akun Instagram pribadinya sehingga dapat menjadikan Rachel Vennya seorang online personal influencer dimana Ia dapat membentuk opini masyarakat terutama pada kelompok pengguna media sosial terutama yang berusia berkisar antara 1825 tahun untuk membeli produk yang Ia pasarkan.
Melihat antusias masyarakat Indonesia terhadap Instagram Niko Al-Hakim, pemilik usaha Sate Taichan Goreng menggunakan peluang ini untuk lebih dekat dengan konsumennya. Menurut data yang dikutip dari tempo.com, pengguna media sosial Instagram di Indonesia merupakan yang terbesar di Asia Pasifik serta salah satu pasar terbesar di dunia dari total 700 juta pengguna aktif setiap bulan. Ia menggunakan jasa Rachel Vennya untuk memasarkan usahanya. Dapat dikatakan strategi pemasaran yang dilakukan oleh Niko ini cukup efektif dan usahanya berkembang sangat pesat.

Agar usaha yang dijalani tetap terus berkembang dan tujuan organisasi dapat tercapai, para pelaku usaha harus memperhatikan kualitas dari produk yang mereka jual, karena kualitas produk dapat menjadi faktor penentu tingkat kepuasan yang diperoleh pembeli setelah melakukan pembelian dan pemakaian terhadap suatu produk.

Secara konseptual, produk adalah pemahaman subyektif dari produsen atas 'sesuatu' yang bisa ditawarkan sebagai usaha untuk mencapai tujuan organisasi melalui pemenuhan kebutuhan dan keinginan konsumen, sesuai dengan kompetensi dan kapasitas organisasi serta daya beli pasar (Tjiptono, 2008:95). Sedangkan kualitas merupakan perpaduan antara sifat dan karakteristik yang menentukan sejauh mana keluaran dapat memenuhi persyaratan kebutuh pelanggan. Faktor inilah yang nantinya akan membuat sebuah keputusan apakah konsumen tersebut akan melakukan pembelian kembali atau tidak.

Karena usaha yang dipasarkan oleh Rachel ada di bidang makanan, konsumen tentu saja mengharapkan adanya kesesuaian antara harga dengan kualitas produk yang mereka terima. Sebagai contoh untuk produk makanan, rasa, tekstur, selera, dan penampilan akan menjadi sebuah ukuran bagi konsumen untuk melakukan pembelian bahkan pembelian ulang akan terjadi jika 
konsumen merasa puas oleh makanan yang mereka konsumsi.

Tujuan penelitian ini adalah untuk:

a. Menganalisis pengaruh celebrity endorser (Rachel Vennya) terhadap keputusan pembelian Sate Taichan "Goreng".

b. Menganalisis pengaruh kualitas produk terhadap keputusan pembelian Sate Taichan "Goreng”.

c. Menganalisis variabel yang lebih berpengaruh terhadap keputusan pembelian Sate Taichan "Goreng”.

Adapun manfaat penelitian ini adalah untuk menerapkan teori-teori yang dipeoleh selama perkuliahan, kemudian memperdalam pengetahuan dan wawasan dalam bidang manajemen pemasaran, khususnya dalam memahami dan mengimplementasikannya serta sebagai sumbangan pikiran kepada perusahaan untuk mengambil kebijaksanaan dalam mengetahui perilaku konsumen dalam keputusan pembelian Sate Taichan “Goreng”.

\section{Rumusan Masalah}

Berdasarkan latar belakang diatas, maka dapat dirumuskan permasalahan sebagai berikut:

a. Seberapa besar celebrity endorser mempengaruhi keputusan pembelian?

b. Seberapa besar kulitas produk mempengaruhi keputusan pembelian?

c. Manakah yang lebih berpengaruh terhadap keputusan pembelian, celebrity endorser atau kualitas produk?

\section{Tinjauan Pustaka \\ Celebrity Endorser}

Dalam menjalankan usahanya, pelaku usaha harus memperhatikan perilaku konsumen di pasar sasarannya sehingga dapat menerapkan salah satu dari empat bauran pemasaran, yaitu promosi, yang baik sehingga tujuan perusahaan dapat tercapai. Dari sekian banyak metode dan usaha untuk memasarkan produk yang dijual, salah satu cara yang efektif untuk memasarkan produk adalah dengan menggunakan celebrity endorser.

Selebriti adalah tokoh (aktor, penghibur, atau atlet yang dikenal masyarakat karena prestasinya di dalam bidang-bidang yang berbeda dari golongan produk yang didukung. Endorser adalah pendukung iklan atau yang dikenal juga sebagai bintang iklan untuk mendukung suatu produk. Sedangkan celebrity endorser adalah strategi pemasaran dengan menggunakan selebriti yang disukai dan dihormati oleh khalayak dan diharapkan dapat mempengaruhi sikap dan perilaku konsumen yang baik terharap produk yang didukung (Shimp, 2003:460).

Royan dalam Nuraini (2015:24) mengatakan bahwa alasan yang menyebabkan selebriti sangat diminati oleh produsen untuk mengiklankan produknya adalah karena pesan yang disampaikan oleh sumber yang menarik (kaum selebriti yang sedang populer) akan mendapat perhatian yang lebih besar disamping akan sangat mudah diingat.

Shimp dalam Nuraini (2015:25) mengatakan bahwa terdapat atribut-atribut pendukung dan peranan celebrity endorser dalam mencapai efektivitas komunikasi yang mana masing-masing atribut tersebut memiliki mekanisme yang berbeda akan pendukung yang mempengaruhi perilaku. Atribut-atribut tersebut adalah:

a. Dapat dipercaya (trustworthiness) Mengacu pada kejujuran, integritas dan kepercayaan diri dari seorang sumber pesan.

b. Keahlian (expertise)

Mengacu pada pengetahuan, pengalaman atau keahlian yang dimiliki oleh seorang endorser yang dihubungkan dengan merek yang didukung seorang endorser yang diterima sebagai seorang yang ahli pada merek yang didukungnya akan lebih persuasif dalam menarik audience daripada seorang endorser yang tidak diterima sebagai seorang yang ahli.

c. Daya tarik fisik (attractiveness) 
Mengacu pada diri yang dianggap sebagai hal yang menarik untuk dilihat dalam kaitannya dengan konsep kelompok tertentu dengan daya tarik fisik.

d. Kualitas dihargai (respect)

Kualitas yang dihargai atau digemari sebagai akibat dari kualitas pencapaian personal.

e. Kesamaan dengan audience yang dituju (similarity) Mengacu pada kesamaan antara endorser dan audience dalam hal umur, jenis kelamin, etnis, status sosial, dan sebagainya.

\section{Kualitas Produk}

Dalam menjalankan suatu bisnis, produk maupun jasa yang dijual harus memiliki kualitas yang baik atau sesuai dengan harga yang ditawarkan. Hal ini bertujuan agar suatu usaha atau perusahaan dapat bertahan dalam menghadapi persaingan, terutama persaingan dari segi kualitas, perusahaan perlu terus meningkatkan kualitas produk atau jasanya. Karena peningkatan kualitas prosuk dapat membuat konsumen merasa puas terhadap produk atau jasa yang mereka beli, dan akan mempengaruhi konsumen untuk melakukan pembelian ulang.

Tjiptono, dkk. (2008:68) menyatakan bahwa ada delapan dimensi kualitas produk, yaitu:

a. Kinerja (performance), karakteristik dasar dari suatu produk inti yang dibeli.

b. Fitur (feature), karakteristik pelengkap khusus yang dapat menambah pengalaman pemakaian produk.

c. Keandalan (reliability), yaitu probabilitas terjadinya kegagalan atau kerusakan produk dalam periode waktu tertentu. Semakin kecil kemungkinan terjadi kerusakan maka semakin andal produk yang bersangkutan. d. Konformasi (conformance), yaitu tingkat kesesuaian produk dengan standar yang telah ditetapkan.

e. Daya tahan (durabillity), yaitu jumlah pemakaian produk sebelum produk bersangkutan harus diganti.

f. Kemampulayanan (service ability), meliputi kecepatan, kompetensi, kenyamanan, mudah direparasi, serta penanganan keluhan yang memuaskan.

g. Estetika (aesthetic), yaitu menyangkut penampilan produk yang dapat dinilai dengan panca inera (rasa, aroma, suara, dan seterusnya).

h. Persepsi terhadap kualitas (perceived quality), yaitu kualitas yang dinilai berdasarkan reputasi penjual.

\section{Keputusan Pembelian}

Perilaku konsumen dalah melakukan pembelian cukup kompleks. Bahkan jika konsumen sudah membentuk evaluasi merek, ada beberapa faktor yang dapat mengintervensi anatara maksud pembelian dan keputusan pembelian. Kotler dan Keller (2009:189) menjelelaskan mengenai faktor pengintervensi dalam keputusan pembelian, faktor-faktor tersebut adalah:

a. Sikap orang lain

Dalam melakukan sebuah pembelian, sikap orang lain dapat menjadi sebuah pengintervensi bagi konsumen. Batas dimana sikap seseorang mengurangi preferensi konsumen untuk sebuah alternatif tergantung pada dua hal: (1) intensitas sikap negatif orang lain terhadap alternatif yang kita sukai dan (2) motivasi kita untuk mematuhi kehendak orang lain. Semakin intens sikap negatif orang lain dan semakin dekat hubungan orang tersebut dengan kita, semakin besar kemungkinan kita 
menyesuaikan niat pembelian kita, hal sebaliknya juga berlaku.

b. Faktor situasional yang tidak diantisipasi

Faktor ini seringkali muncul untuk mengubah niat pembelian. Kotler dan Armstrong (2008:181) menjelaskan bahwa yang menjadi faktor situasional yang tidak diantisipasi adalah pendapatan, harga, dan manfaat produk yang diharapkan.

c. Niat untuk membeli

Niat untuk membeli merupakan salah satu proses dalam pembelian suatu barang sebelum akhirnya mengambil keputusan untuk membeli produk tersebut. Niat beli didasari oleh pengalaman dalam memilih, menggunakan, mengkonsumsi, atau bahkan mengingat suatu produk.

d. Evaluasi alternatif

Setelah mencari informasi, konsumen akan dihadapkan kepada sejumlah merek yang dapat dipilih. Konsumen menggunakan informasi untuk mengevaluasi merek alternatif dalam sekelompok pilihan.

\section{HASIL DAN PEMBAHASAN}

Tempat penelitian penelitian ini adalah Sate Taichan "Goreng” yang beralamat di Jl. Tebet Raya No.70, RT.2/RW.4, Tebet Tim., Tebet, Kota Jakarta Selatan, Daerah Khusus Ibukota Jakarta 12820 Obyek dalam penelitian ini adalah konsumen pada Sate Taichan "Goreng” Cabang Tebet.

Jenis data yang digunakan adalah data primer yang didapatkan peneliti dari kuesioner yang diberikan kepada konsumen Sate Taichan "Goreng” Cabang Tebet dan data sekunder yang bersal dari literatur, buku, artikel, jurnal, penelitian terdahulu, maupun data dari internet.

\section{Populasi dan Sampel}

Sampel yang digunakan peneliti berjumlah 96,04 yang dibulatkan menjadi 100 orang berdasarkan rumus jumlah sampel oleh Lemeshow sebagai berikut:

$$
\mathrm{n}=Z^{2} \cdot P(1-P) / d^{2}
$$

Keterangan:

n: Jumlah sampel

Z: Skor Z pada kepercayaan 95\% $=95 \%$

P: Maksimal estimasi

d: Alpha

Perhitungan jumlah sampel yang didapatkan adalah sebagai berikut

$$
n=1,96^{2} \cdot \frac{0,5(1-0,5)}{0,10^{2}}=96,04
$$

Cara pengambilan sampel dalam penelitian ini dilakukan dengan menggunakan metode nonprobability sampling dengan teknik incidental sampling atau teknik penentuan sampel berdasarkan kebetulan, yaitu siapa saja yang secara kebetulan atau incidental bertemu dengan peneliti.

\section{Teknik Analisis Data}

Teknik analisis data yang digunakan untuk menguji hipotesis penelitian ini adalah:

a. Uji instrumen, terdiri dari uji validitas menggunakan korelasi product moment dengan kriteria rhitung $>$ rtabel, serta uji reliabilitas dengan nilai cronbach alpha $>0,70$.

b. Uji asumsi klasik, terdiri dari uji normalitas dengan kriteria nilai probabilitas sig > taraf signifikansi $\alpha$, uji multikolinearitas dengan kriteria apabila nilai tolerance $>0,1$ dan nilai VIF $<10$ serta uji heterokedastisitas dengan menggunaan grafik scatterplot.

c. Uji hipotesis, terdiri dari analisis regresi linear berganda untuk mengetahui untuk mengetahui arah hubungan antara variabel independen dan variabel dependen., uji koefisien determinasi untuk mengetahui pengaruh/kontribusi X1 dan X2 terhadap Y, uji signifikansi t untuk mengetahui apakah masing- 
masing variabel bebasnya secara sendiri-sendiri berpengaruh secara signifikan terhadap variabel terikatnya, serta uji simultan untuk mengetahui pengaruh secara simultan atau bersama-sama antar variabel independen terhadap variabel dependen.

Pembahasan hasil penelitian setelah melalui tahap pengumpulan, pengolahan, dan analisis data adalah sebagai berikut:

a. Uji validitas dan uji reliabilitas dilakukan kepada 20 responden penelitian. Kuesioner penelitian terdiri dari pernyataan terkait variabel celebrity endorser dan variabel kualitas produk, dengan nilai rhitung > rtabel $(0,3783)$ yang terdiri dari 100 butir pernyataan yang valid. Kuesioner pada penelitian ini dikatakan reliabel dengan nilai relibilitas 0,966 untuk variabel celebrity endorser, 0,989 untuk variabel kualitas produk, dan 0,972 untuk variabel keputusan pembelian.

b. Perhitungan uji normalitas pada penelitian ini dilakukan dengan tiga metode, yaitu Kolmogorov Smirnov, histogram, dan p-plot. Hasil dari uji normalitas menggunakan perhitungan Kolmogorov Smirnov menunjukkan nilai Asymp Sig. sebesar $0,150>$ nilai taraf signifikansi 0,1 , sehingga data penelitian berdistribusi normal. Berikut hasil perhitungan dengan Kolmogorov Smirnov:

Tabel 1. Kolmogorov Smirnov

One-Sample Kolmogorov-Smirnov Test

\begin{tabular}{|ll|r|}
\hline & & $\begin{array}{r}\text { Unstandardiz } \\
\text { ed Residual }\end{array}$ \\
\hline Normal Parameters & a,b & Mean \\
& Std. Deviation &, 0000000 \\
Most Extreme Differences & 4,19139097 \\
& Absolute &, 077 \\
& Positive &, 070 \\
Test Statistic & Negative &,- 077 \\
Asymp. Sig. (2-tailed) & &, 077 \\
\hline
\end{tabular}

Sumber: data diolah, 2018
Hasil perhitungan normalitas dengan histogram adalah sebagai berikut:

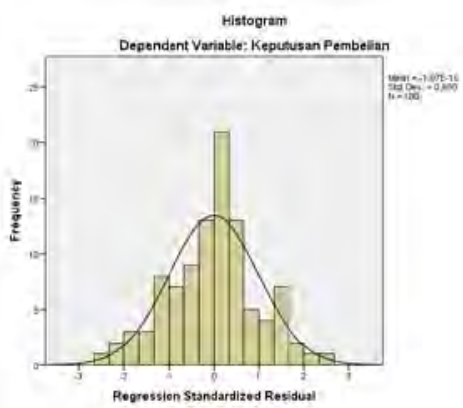

Gambar 1. Histogram (Sumber: data diolah, 2018)

Hasil uji normalitas di atas menunjukkan bentuk histogram yang telah mengikuti kurva, yang memiliki arti bahwa data penelitian berdistribusi normal. Hal ini sejalan dengan hasil p-plot yang menunjukkan persebaran titik berada di dekat garis diagonal sebagai berikut:

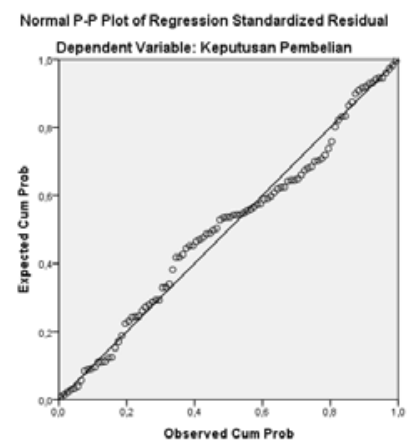

Gambar 2. P-Plot (Sumber: data diolah, 2018)

c. Hasil uji multikolinearitas diperoleh nilai tolerance adalah $0,85>0,1$ dan VIF $1,167<10$. Hal ini berarti bahwa tidak ada multikolinearitas antar variabel independen dalam model regresi, sehingga model regresi layak dipakai untuk memprediksi keputusan pembelian berdasarkan masukan variabel celebrity endorser dan kualitas produk. 
Tabel 2. Hasil Uji Multikolinearitas

\begin{tabular}{|c|c|c|c|c|}
\hline \multirow{2}{*}{ Model } & \multirow{2}{*}{ Sig. } & \multicolumn{2}{|c|}{ Collinearity Statistics } \\
\cline { 4 - 5 } & & Tolerance & VIF \\
\hline \multirow{2}{*}{\begin{tabular}{c}
$*$ \\
\multirow{2}{*}{1}
\end{tabular}} & (Constant) &, 000 & & \\
\cline { 4 - 5 } & $\begin{array}{c}\text { Celebrity } \\
\text { Endorser }\end{array}$ &, 000 &, 857 & 1,167 \\
& Kualitas Produk &, 098 &, 857 & 1,167 \\
\hline
\end{tabular}

Sumber: data diolah, 2018

d. Hasil uji regresi linear berganda diperoleh persamaan $\mathrm{Y}=41,524+$ $0,281 \mathrm{X} 1+0,069 \mathrm{X} 2$. Hasil menunjukkan adanya hubungan linier dan positif dimana artinya jika celebrity endorser ditingkatkan 1 nilai, maka keputusan pembelian konsumen terhadap Sate Taichan “Goreng” naik sebesar 0,28 dan jika kualitas produk ditingkatkan 1 nilai, maka keputusan pembelian konsumen terhadap Sate Taichan “Goreng” naik sebesar 0,069.

Tabel 3. Hasil Uji Analisis Linier Berganda

\begin{tabular}{|c|c|c|c|c|}
\hline \multirow[b]{2}{*}{ Model } & \multicolumn{2}{|c|}{$\begin{array}{c}\text { Unstandardized } \\
\text { Coefficients }\end{array}$} & \multirow[b]{2}{*}{$\mathrm{t}$} & \multirow[b]{2}{*}{ Sig. } \\
\hline & B & Std. Error & & \\
\hline $\begin{array}{ll}1 & \text { (Constan } \\
\text { t) }\end{array}$ & 41,524 & 6,622 & 6,270 & ,000 \\
\hline $\begin{array}{l}\text { Celebrity } \\
\text { Endorser }\end{array}$ & 281 & ,040 & 7,051 & ,000 \\
\hline $\begin{array}{l}\text { Kualitas } \\
\text { Produk }\end{array}$ & ,069 & , 041 & 1,673 & ,098 \\
\hline
\end{tabular}

Sumber: data diolah, 2018

e. Hasil peritungan koefieisn determinasi didapatkan hasil $\mathrm{r}^{2}$ sebesar 0.425. Hal ini berarti sebesar 42,5\% keputusan konsumen untuk membeli Sate Taichan "Goreng" dipengaruhi oleh Rachel Vennya sebagai celebrity endorser dan kualitas produk dengan perhitungan secara parsial pengaruh variabel celebrity endorser adalah sebesar $(0,639)^{2} \times 100 \%=40,83 \%$ dan pegaruh variabel kualitas produk adalah sebesar:

$(0,361)^{2} \times 100 \%=13,03 \%$.
Tabel 4. Hasil Uji Koefisien Determinasi $\left(\mathrm{R}^{2}\right)$

Model Summary
\begin{tabular}{|l|c|c|c|c|}
\hline Model & R & R Square & $\begin{array}{c}\text { Adjusted R } \\
\text { Square }\end{array}$ & $\begin{array}{c}\text { Std. Error of } \\
\text { the Estimate }\end{array}$ \\
\hline 1 &, $652^{\text {a }}$ &, 425 &, 413 & 4,234 \\
\hline
\end{tabular}
a. Predictors: (Constant), Kualitas Produk, Celebrity Endorser
b. Dependent Variable: Keputusan Pembelian

Sumber: data diolah, 2018

Tabel 5. Hasil Korelasi secara Parsial

\begin{tabular}{|ll|r|}
\hline & & $\begin{array}{r}\text { Keputusan } \\
\text { Pembelian }\end{array}$ \\
\hline Celebrity & Pearson Correlation &, $639^{* *}$ \\
Endorser &, 000 \\
& Sig. (2-tailed) & 100 \\
& $\mathrm{~N}$ &, $361^{\text {** }}$ \\
\hline Kualitas & Pearson Correlation &, 000 \\
Produk & Sig. (2-tailed) & 100 \\
& $\mathrm{~N}$ & 1 \\
\hline Keputusan & Pearson Correlation & \\
Pembelian & Sig. (2-tailed) & 100 \\
& $\mathrm{~N}$ & \\
\hline
\end{tabular}

Sumber: data diolah, 2018

f. Hasil pengujian nilai t untuk variabel celebrity endorser menunjukkan nilai $t_{\text {hitung }}=7,051>t_{\text {tabel }}=1,66071$ dan signifikansi sebesar $0,000<0,10$ dengan demikian berarti variabel celebriy endorser secara parsial berpengaruh positif terhadap keputusan pembelian Sate Taichan "Goreng” pada konsumen Sate Taichan "Goreng” Cabang Tebet. Sedangkan hasil pengujian pengujian nilai $\mathrm{t}$ untuk variabel kualitas produk menunjukkan nilai $\mathrm{t}_{\text {hitung }}=1,673>\mathrm{t}_{\text {tabel }}=1,66071, \quad$ dan perhitungan signifikansi sebesar $0,098<0,10$, yang berarti terdapat pengaruh antara variabel kualitas produk terhadap keputusan pembelian Sate Taichan "Goreng” pada konsumen Sate Taichan "Goreng" Cabang Tebet.

Tabel 6. Hasil Uji T

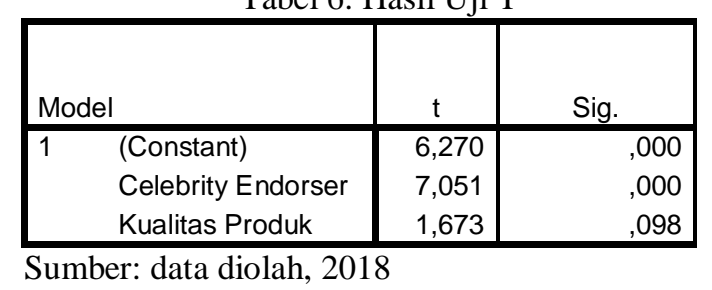

Sumber: data diolah, 2018 
g. Berdasarkan hasil perhitungan statistik, nilai $\quad F_{\text {hitung }}=35,840>$ $\mathrm{F}_{\text {tabel }}=2,36$ dan nilai signifikansi sebesar $0,000<0,10$. Hal ini menunjukkan bahwa variabel independen pada penelitian ini, yaitu celebrity endorser dan kualitas produk mempunyai pengaruh yang signifikan terhadap keputusan pembelian. Hal ini berarti kualitas produk secara bersama-sama berpengaruh terhadap keputusan pembelian Sate Taichan "Goreng" pada konsumen Sate Taichan "Goreng” Cabang Tebet. Tabel 7. Hasil Uji F

\begin{tabular}{|ll|r|c|c|}
\hline \multicolumn{1}{|l|}{ Model } & Mean Square & $\mathrm{F}$ & \multicolumn{1}{c|}{ Sig. } \\
\hline 1 & $\begin{array}{l}\text { Regression } \\
\text { Residual } \\
\text { Total }\end{array}$ & 642,616 & 35,840 &, $000^{\mathrm{b}}$ \\
\multicolumn{2}{|c|}{17,930} & & \\
\hline
\end{tabular}

Sumber: data diolah, 2018

\section{KESIMPULAN DAN SARAN}

\section{Kesimpulan}

a. Celebrity endorser (Rachel Vennya) berpengaruh positif dan signifikan terhadap keputusan pembelian Sate Taichan "Goreng” Cabang Tebet. Hal ini dibuktikan dengan hasil hitung secara parsial dengan $t_{\text {hitung }}=7,051>t_{\text {tabel }}=1,66071$ dan nilai signifikansi sebesar 0,000 $<0,10$. Hasil perhitungan statistik menunjukkan bahwa Rachel Vennya sebagai celebrity endorser berpengaruh sebesar 40,83\% terhadap keputusan pembelian konsumen dan mengacu pada pembahasan di bab IV, indikator yang paling berpengaruh pada celebrity endorser adalah trustworthiness.

b. Kualitas produk berpengaruh positif terhadap keputusan pembelian Sate Taichan "Goreng" Cabang Tebet. Hal ini dibuktikan dengan hasil hitung secara parsial $t_{\text {hitung }}=1,673>t_{\text {tabel }}=1,66071$ dan nilai signifikansi sebesar $0,098<0,10$. Hasil perhitungan statistik menunjukkan bahwa kualitas produk Sate Taichan "Goreng” berpengaruh sebesar 13,03\% dan mengacu pada pembahasan di bab IV, indikator yang paling berpengaruh pada variabel kualitas produk adalah keandalan.

c. Celebrity endorser dan kualitas produk secara bersama-sama berpengaruh positif terhadap keputusan pembelian Sate Taichan “Goreng” pada konsumen Sate Taichan "Goreng" Cabang Tebet sebesar $42,5 \%$ dan variabel yang paling berpengaruh pada keputusan pembelian Sate Taichan "Goreng" adalah celebrity endorser.

\section{Saran}

a. Peran Rachel Vennya sebagai celebrity endorser pada media sosial Instagram memberikan pengaruh yang positif dengan unsur yang paling mempengaruhi keputusan pembelian konsumen adalah trustworthiness atau rasa percaya masyarakat terhadap Rachel Vennya. Tingkat kepercayaan ini merupakan hal yang tidak bisa lepas apabila sebuah perusahaan hendak memilih selebriti untuk mendukung usahanya. Oleh karena itu untuk celebrity endorser, diperlukan usaha menjaga kepercayaan tersebut dengan mengiklankan produk-produk yang berkualitas baik.

b. Sate Taichan "Goreng" perlu memperhatikan unsur kesamaan (similarity) yang dimiliki oleh celebrity endorser dan konsumennya. Maksud dari kesamaan di sini meliputi kesamaan sifat, kesamaan kebutuhan, kesamaan kegemaran, dan lain-lain. Menggunakan jasa celebrity endorser yang banyak kesamaan atau kemiripan antara sumber dengan konsumen dapat 
dilakukan sehingga iklan tersebut akan menarik perhatian bahkan dapat mempengaruhi konsumen untuk membeli produk Sate Taichan "Goreng".

c. Kualitas produk merupakan aspek yang sangat penting bagi pelaku usaha dibidang makanan dalam tujuan memperkuat pangsa pasar. Keandalan produk yang dihasilkan Sate Taichan "Goreng” sudah baik. Hal ini berarti konsumen sudah cukup puas dengan rasa, kebersihan, dan keamanan dari produk ini. Agar konsumen tetap percaya dengan Sate Taichan "Goreng”, kualitas dari produk yang dihasilkan ini perlu di jaga agar tetap baik.

d. Unsur yang perlu diperhatikan oleh Sate "Gaichan "Goreng" menyangkut kualitas produknya adalah daya tahan. Mengingat produk yang dihasilkan oleh Sate Taichan "Goreng” adalah makanan, diperlukan cara agar makanan tetap enak walaupun tidak langsung di konsumsi. Menggunakan alumunium voil sebagai pembungkus makanan dapat dilakukan agar makanan tetap hangat sehingga masih terasa enak walaupun tidak langsung dikonsumsi.

\section{UCAPAN TERIMA KASIH}

Seluruh pihak yang tidak dapat Penulis sebutkan satu persatu atas support dan bantuannya dalam penyusunan jurnal ini. Penulis menyadari bahwa dalam penyusunan jurnal ini masih banyak kekurangan. Oleh karena itu, Penulis mengharapkan saran dan kritik yang membangun dari semua pihak agar menjadi bahan evaluasi bagi Penulis dalam membuat karya tulis ilmiah selanjutnya dikemudian hari.

\section{DAFTAR PUSTAKA}

\section{Buku}

Belch, George dan Belch, Michael. 2007. Advertising and Promotion. $7^{\text {th }}$ Edition. The McGraw-Hill Companies.

Fill, Chris. 2013. Marketing Communications. Pearson.

Ghozali, Imam. 2016. Aplikasi Analisis Multivariete dengan Program IBM SPSS.23. Semarang: BPFE Universitas Diponegoro.

Kotler, Philip dan Gary Amstrong. 2008. Prinsip-Prinsip Pemasaran. Edisi 12. Jilid 1. Jakarta: Erlangga.

Kotler, Philip dan Keller, L.Kevin. 2009. Manajemen Pemasaran. Jilid 1. Edisi 13. Jakarta: Erlangga.

Schiffman dan Kanuk. 2008. Perilaku Konsumen Edisi 7. Jakarta: Indeks.

Siregar, Syofyan. 2013. Metode Penelitian Kuantitatif. Dilengkapi dengan Perbandingan Perhitungan Manual. Jakarta: Kencana. Edisi 13. Jakarta: Erlangga.

Sugiyono. 2011. Metode Penelitian Administratif. Bandung: CV Alfabeta.

--------. 2017. Metode Penelitian: Kuantitatif Kualitatif dan $R \& D$. Bandung: CV Alfabeta.

Suharso, Puguh. 2012. Metode Penelitian Kuantitatif untuk Bisnis. Jakarta: Indeks.

Tjiptono, Fandy. 2008. Strategi Pemasaran. Edisi 3. Yogyakarya: CV Andi Offset. 
